\title{
There must be an acetogen somewhere
}

\begin{abstract}
Aharon Oren*
Department of Plant and Environmental Sciences, The Alexander Silberman Institute of Life Sciences, The Hebrew University of Jerusalem, Jerusalem, Israel

${ }^{*}$ Correspondence: orena@cc.huji.ac.il
\end{abstract}

\section{A commentary on}

Acetogenesis in the energy-starved deep biosphere - a paradox?

by Mark Alexander Lever (2012). Front. Microbiol.2:284. doi: 10.3389/fmicb.2011.00284

In the beginning of 1983, when I was a post-doctoral student at the University of Illinois, Ralph Wolfe handed me an offprint of a long article and said: "Read this!" That paper was the review by Thauer et al. (1977) on "Energy conservation in chemotrophic anaerobic bacteria." I have read it many times. I remember that the first and second time I understood very little. During the third and fourth reading I started to grasp the ideas expressed and to appreciate them. And after having read the paper for the fifth and sixth time I had become convinced that microbial metabolism and metabolic diversity can only be properly understood using the kind of thermodynamic analyses on which Thauer and his colleagues based their review. Until this day I use this thermodynamic approach to explain the functioning of the microbial world in the basic and more advanced microbiology courses I teach.

At the same time Ralph Wolfe also introduced me to the world of the acetogens. I still remember how excited he was that the culture of Clostridium aceticum, isolated in the $1930 \mathrm{~s}$ (Wieringa, 1936) but subsequently considered as lost, had been revived from a preparation of endospores of the original strain and thus became again available for study (Braun et al., 1981). The place of the acetogens in nature, and especially those species that live as autotrophs on hydrogen as their energy source, has always been enigmatic. The reason becomes immediately obvious when calculating the thermodynamics of the process, comparing the Gibbs free energy change under standard conditions of three competing processes: sulfate reduction, methanogenesis, and homoacetogenic metabolism:

$$
\begin{aligned}
& 4 \mathrm{H}_{2}+\mathrm{SO}_{4}^{2-}+\mathrm{H}^{+} \rightarrow \mathrm{HS}^{-}+4 \mathrm{H}_{2} \mathrm{O} \\
& \Delta \mathrm{G}_{\mathrm{o}}^{\prime}=-152.2 \mathrm{~kJ}
\end{aligned}
$$

$$
\begin{aligned}
& 4 \mathrm{H}_{2}+\mathrm{HCO}_{3}^{-}+\mathrm{H}^{+} \rightarrow \mathrm{CH}_{4}+3 \mathrm{H}_{2} \mathrm{O} \\
& \Delta \mathrm{G}_{\mathrm{o}}^{\prime}=-135.6 \mathrm{~kJ} \\
& 4 \mathrm{H}_{2}+2 \mathrm{HCO}_{3}^{-}+\mathrm{H}^{+} \rightarrow \mathrm{CH}_{3} \mathrm{COO}^{-}+4 \mathrm{H}_{2} \mathrm{O} \\
& \Delta \mathrm{G}_{\mathrm{o}}^{\prime}=-104.6 \mathrm{~kJ}
\end{aligned}
$$

As long as sulfate is available, sulfate reducers will consume most of the hydrogen. They obtain more energy from hydrogen oxidation, and their affinity for hydrogen is much higher than that of the methanogenic Archaea, explaining why the methanogens are out-competed when the energy source is limiting (Kristjansson et al., 1982). When sulfate is limiting, methanogens will take over. No similar competition studies between methanogens and acetogens were ever reported, but based on the lower energy yield of the acetogenic reaction it is highly probably that the acetogens will lose the competition. Recent calculations confirm this: assuming a "biological energy quantum" (the minimum amount of free energy change of a reaction that can drive the formation of ATP) of $-10 \mathrm{~kJ}$, the thermodynamic threshold concentrations of $\mathrm{H}_{2}$ calculated for chemolithoautotrophic sulfate reducers, methanogens, and acetogens are $\sim 0.6,11$, and $410 \mathrm{nM}$, respectively (Lever, 2011). These numbers clearly show that the "homoacetogenic" reaction from $\mathrm{H}_{2}-\mathrm{CO}_{2}$ is thermodynamically unfavorable. The advantage of the methanogens over the acetogens is also demonstrated in the following calculation: at partial pressures for hydrogen and for methane of $10^{-4}$ and $0.5 \mathrm{~atm}$, respectively, and bicarbonate, and acetate concentrations of 100 and $10 \mathrm{mM}$, the Gibbs free energy is $-40 \mathrm{~kJ}$ per reaction for the formation of methane from bicarbonate and hydrogen, but only $-13 \mathrm{~kJ}$ for the formation of acetate. Dolfing (1988) wrote: "A meaningful evaluation of the energy conservation and the selection mechanism that govern the outcome of competition between methanogens and acetogens has to wait until more data are available on (growth parameters) $\mu, K_{\mathrm{s}}$, $K_{\mathrm{m}}, Y$, and $q$ of these organisms, preferably obtained in chemostat experiments." To my knowledge no such experiments have yet been performed.

The question therefore remains where in nature the acetogens can out-compete the methanogens. In recent years evidence is accumulating that, unexpectedly, acetogens may represent a quantitatively important component of the microbial ecosystem in the oligotrophic marine and terrestrial deep biosphere. The paper by Lever provides an in-depth analysis of the possible factors that give the acetogens advantages in this vast, but largely unexplored niche. Lever argues that under conditions encountered in the subseafloor, the energy yields of most acetogenesis reactions are sufficient to support growth. Furthermore, acetogens have a remarkable metabolic flexibility compared to methanogens and sulfate reducers, and can use more substrates or substrate combinations as energy source. Moreover, the fact that they use the energyefficient reductive acetyl-CoA pathway (also known as the Wood-Ljungdahl pathway) both for autotrophic carbon fixation and for energy production makes their metabolism highly efficient, enabling them to save precious energy for survival when stressed (Lever, 2011).

The title of this commentary - "There must be an acetogen somewhere" paraphrases Woese's (1994) "There must be a prokaryote somewhere." Nobody can have any doubt that prokaryotes play a central function in nature, but the role of the acetogens was never really clear. Therefore Lever's paper contributes much toward a proper assessment of the place of this intriguing group of prokaryotes in anaerobic ecosystems worldwide.

\section{REFERENCES}

Braun, M., Mayer, F., and Gottschalk, G. (1981). Clostridium aceticum (Wieringa), a microorganism producing acetic acid from molecular hydrogen and carbon dioxide. Arch. Microbiol. 128, 188-293. 
Dolfing, J. (1988). "Acetogenesis," in Environmental Microbiology of Anaerobes, ed. A. J. B. Zehnder (New York: John Wiley \& Sons), 417-468.

Kristjansson, J.K., Schönheit, P., and Thauer, R. K. (1982). Different Ks values for hydrogen of methanogenic bacteria and sulfate reducing bacteria: an explanation for the apparent inhibition of methanogenesis by sulfate. Arch. Microbiol. 131, 278-283.

Lever, M. A. (2011). Acetogenesis in the energy-starved deep biosphere - a paradox? Front. Microbiol. 2, 284. doi: 10.3389/fmicb.2011.00284
Thauer, R. K., Jungermann, K., and Decker, K. (1977). Energy conservation in chemotrophic anaerobic bacteria. Bacteriol. Rev. 41, 100-180.

Wieringa, K. T. (1936). Over het verdwijnen van waterstof en koolzuur onder anaerobe voorwaarden. Antonie van Leeuwenhoek 3, 263-273.

Woese, C.R.(1994). There must be a prokaryote somewhere: microbiology's search for itself. Microbiol. Rev. 58, 1-9.

Received: 12 January 2012; accepted: 13 January 2012; published online: 31 January 2012.
Citation: Oren A (2012) There must be an acetogen somewhere. Front. Microbiol. 3:22. doi: 10.3389/ fmicb.2012.00022

This article was submitted to Frontiers in Extreme Microbiology, a specialty of Frontiers in Microbiology. Copyright (๑) 2012 Oren. This is an open-access article distributed under the terms of the Creative Commons Attribution Non Commercial License, which permits non-commercial use, distribution, and reproduction in other forums, provided the original authors and source are credited. 